\title{
“Aqui a gente não faz milagre": Particularidades do tratamento espiritual de doenças no espiritismo kardecista $^{1}$
}

ALLAN WINE SANTOS BARBOSA

\section{Introdução}

As experiências de cura em contextos religiosos vêm se mostrando como instâncias privilegiadas para a reflexão antropológica e sociológica. Indo desde a cura xamânica até os exorcismos neopentecostais - envolvendo a agência de espíritos, santos e sacerdotes na vivência concreta de doenças, dores, sofrimentos e aflições - os tratamentos religiosos e fenômenos de cura por intermédio do sagrado vêm ganhando força com as crescentes disputas no interior da esfera religiosa; e desta com os movimentos seculares que tomam o conhecimento científico convencional como única instância legítima de intervenção terapêutica sobre o corpo ${ }^{2}$. Mais do que isso, inúmeras formas de religiosidade, como o movimento Nova Era, mobilizam experiências heterogêneas de saúde e bem-estar do corpo e da alma. Terapias com cristais, passes energéticos, utilização de substâncias fitoterápicas e práticas advindas de religiões orientais são alguns exemplos de como as religiões têm intensificado seu escopo de ação sobre a dimensão da saúde.

No contexto religioso brasileiro, esse movimento não é recente. Existe um número considerável de estudos dedicados à discussão de curas milagrosas no catolicismo popular - grande parte dos casos circundando a figura da Virgem Maria ou de santos e santas -, práticas xamânicas entre povos indígenas, possessão e ritual no candomblé, terapias espirituais kardecistas, entre outros eixos temáti-

1 Versões preliminares deste texto foram apresentadas nas XIX Jornadas Sobre Alternativas Religiosas en América Latina, realizadas entre os dias 14 e 17 de novembro de 2018 em Santiago, Chile, e na 31 Reunião Brasileira de Antropologia, realizada entre os dias 09 e 12 de dezembro de 2018, Brasília/DF. Agradeço pelos comentários e sugestões recebidos nessas duas instâncias de debate.

2 Isso não significa que não existam movimentos que tensionam tais divisões. Para discussões sobre a construção da espiritualidade enquanto dimensão da saúde e sua relação com políticas públicas e práticas médicas, ver Toniol $(2014 ; 2015)$. 
cos. Busco realizar aqui uma contribuição etnográfica a esse debate, mais especificamente às discussões sobre saúde e doença no espiritismo kardecista, a partir de uma análise centrada tanto na experiência do tratamento quanto nas concepções ideológicas envolvidas na relação entre conhecimento científico secular e agência espiritual. Essa relação é interessante de um ponto de vista antropológico, dado que a história de consolidação do espiritismo no Brasil está imbricada com conflitos e disputas em torno de técnicas terapêuticas e cuidados com o corpo e a alma (Moraes 2017). Começando pelas práticas de receitismo mediúnico, homeopatia e noções do chamado "magnetismo animal", o espiritismo enfrentou, entre os séculos XIX e XX, resistência e sanções legais por parte das autoridades médicas e sanitárias, além do próprio Estado Republicano (Giumbelli 1997b; Arribas 2010). A partir da segunda metade do século XX, o espiritismo voltou a se envolver em controvérsias com médicos e instituições estatais por conta das famosas cirurgias espirituais, que chamaram a atenção da mídia internacional por implicarem em intervenções concretas no corpo e pelas narrativas de curas quase miraculosas ${ }^{3}$. Conforme o espiritismo se institucionalizou e ampliou sua presença na sociedade brasileira, essas modalidades mais extremas de cura e tratamento deram lugar a práticas mais contidas e/ou com maior respaldo na doutrina, como os passes, a desobsessão, a água fluidificada e o atendimento fraterno ${ }^{4}$.

Dado esse histórico de diálogo entre espiritualidade e saúde, o escopo de experiências mediúnicas é bastante variado de um centro espírita para outro - ainda que exista uma pressão para a padronização a partir da FEB (Federação Espírita Brasileira) e outros grupos institucionais. Durante o trabalho de campo para minha pesquisa de mestrado - realizado num pequeno centro espírita da cidade de São Carlos, interior de São Paulo -, tive contato com algumas dessas práticas, apesar de não as ter tomado como objeto principal da análise. O centro em questão, a Instituição Espírita Casa do Caminho, oferecia aos visitantes o rol tradicional de atividades espíritas: passes, palestras, grupos de estudo, orações, atendimento fraterno, além de um conjunto de iniciativas assistenciais junto à comunidade local. Uma de minhas interlocutoras durante o trabalho etnográfico, uma dona de casa que acabara de passar dos 60 anos e que estava frequentando a Casa do Caminho, comentou em mais de uma oportunidade sobre a ausência naquele centro de uma junta médica espiritual que pudesse realizar atendimentos voltados à questão da saúde. Essa limitação do centro, que incomodava Dona Maria ${ }^{5}$, levou-a a buscar um outro centro da vizinhança - a Casa de Caridade Estrada de Luz - que lhe oferecesse esse tipo de atividade.

Meu objetivo neste artigo é utilizar a experiência de Dona Maria ao buscar um centro que realizasse consultas e tratamentos espirituais para discutir algumas características que marcam a relação entre espiritismo e saúde, assim como o modo pelo qual essa religião concebe a possibilidade de diferentes registros ideológicos (a ciência e o sagrado) apreenderem um mesmo mundo. Essa questão é mobilizada por meio de um contraste com a noção de milagre ${ }^{6}$ presente no catolicismo e sua importância

3 Sobre cirurgias espirituais e tensões com o espiritismo institucionalizado, ver Souza (2014).

4 Para um levantamento das modalidades de tratamento oferecidas comumente nos centros espíritas, vale a pena citar o trabalho de Lucchetti (2013), sobre terapias complementares nos centros espíritas de São Paulo.

5 A pedido da interlocutora, seu nome e o da instituição que conduz as consultas espirituais foram substituídos.

6 Uma discussão sobre as dificuldades em delimitar o sentido da noção de milagre, bem como distinções teóricas em relação às noções de magia e "maravilha" (wonder), pode ser encontrado no artigo de Shanafelt (2004). Utilizo aqui a acepção teológica clássica de miracula tal como descrita por Benedicta Ward (1987), isto é, como manifestaçôes da agência divina no mundo, embora, como ficará claro adiante, essa caracterização tenha comportado disputas acerca dos tipos de eventos que poderiam ser classificados nessa rubrica. 
na articulação histórica entre natureza e religião. No caso do kardecismo, como buscarei demonstrar, as técnicas e retóricas envolvidas nos procedimentos espirituais tornam visíveis uma série de tensões e articulações importantes no interior da doutrina quando o assunto é a intervenção sobre doenças, aflições e sofrimentos. Tais tensões mobilizam valores importantes na religião, como evolução, carma e expiação, além de problematizar a relação entre o conhecimento espírita do cosmos e a medicina secular convencional. Utilizo alguns elementos da abordagem fenomenológica de Thomas Csordas (1994; 2008) para apreender como tais questões ganham concretude no modo como os pacientes sentem e entendem as transformações advindas da agência espiritual (e médica) sobre seus corpos/espíritos. Por fim, traço uma discussão sobre como as tensões citadas acima podem ser encaradas como fundamentos da própria eficácia dos tratamentos espirituais no kardecismo, apontando que oposições e disputas entre material e espiritual, ciência e religião, entre outras, ganham contornos complexos e variáveis em situações de sofrimento e busca pelo alívio.

A escolha da trajetória de Dona Maria nos processos de tratamento espiritual como fio condutor da descrição que aqui proponho se deu por uma questão metodológica, pois acompanhei todas as suas idas à Casa de Caridade Estrada de Luz, documentando as impressões e experiências decorrentes. O primeiro contato de Dona Maria com a Estrada de Luz foi através da recomendação de uma amiga não-espírita que sofria com dores nas costas e estava desiludida com a inabilidade dos médicos em diagnosticar a origem do problema, tendo sido posteriormente curada pela ação dos especialistas espirituais. Como se encontrava numa situação análoga, enfrentando dores nas pernas que começavam a lhe prejudicar os afazeres cotidianos, Dona Maria resolveu seguir a recomendação e fazer uma visita à casa espírita. É interessante notar que nenhuma das duas se definem como kardecistas, embora participem com certa regularidade de atividades em centros espíritas e partilhem de crenças emblemáticas, como reencarnação, carma e mediunidade.

Outra razão para a escolha desse caso etnográfico em específico é que a história de Dona Maria é ilustrativa de boa parte das pessoas que buscam tratamentos espirituais. Atormentada por dores constantes nas pernas, buscou sem sucesso um tratamento eficaz com vários médicos e especialistas. Os exames, receitas e bulas já se acumulavam desde o início das muitas idas aos consultórios. Alguns diagnósticos apontavam um problema de artrite, outros culpavam o elevado nível de ácido úrico nos exames sanguíneos, com "soluções" indo da prática de exercícios físicos até um número razoável de medicamentos que nunca pereciam resolver de fato o problema. Essa situação deu força a uma crescente desconfiança diante das habilidades dos médicos convencionais, que pareciam "não saber de nada". A possibilidade de realizar um tratamento espiritual, buscando pela via da religião aquilo que o conhecimento técnico se mostrava incapaz de proporcionar, não encontrou resistência, pois Dona Maria já havia realizado um tratamento desse tipo num centro espírita de outra cidade - com aparente sucesso, ressaltava ela. De toda forma, e esse é um discurso ubíquo nos centros espíritas que realizam tratamentos, não custava tentar mais essa alternativa: "mal não vai fazer". Nesse sentido, enfocar um caso etnográfico com tais características nos permite identificar alguns elementos fundamentais da experiência de cura e tratamento no espiritismo ao mesmo tempo em que possibilita a análise detida de uma descrição concreta do fenômeno. 


\section{A Busca pela Cura}

A Casa de Caridade ${ }^{7}$ Estrada de Luz é um pequeno centro espírita localizado num bairro popular de São Carlos, interior de São Paulo. Seu estatuto enquanto instituição espírita não parece muito definido, dado que não é registrada pela USE (União das Sociedades Espíritas Intermunicipal de São Carlos) e nem conta com uma estrutura física própria - as sessões acontecem na casa de um dos dirigentes. Com efeito, a própria agenda de atividades da casa reflete essa posição, dado que, ao contrário dos centros espíritas mais institucionalizados, a Estrada de Luz apenas realiza reunióes de tratamento, oração, palestras de pequeno porte e passes. A administração da instituição tem um caráter mais pessoal e até mesmo familiar do que os centros maiores, que contam com redes de voluntários e quadros de funcionários. Esse é o caso da Casa do Caminho, uma instituição espírita de médio porte localizada no mesmo bairro da Estrada de Luz e na qual realizei meu trabalho de campo durante o mestrado (Santos Barbosa 2018).

Dona Maria chegou ao centro numa terça-feira, tendo ouvido dizer que nesse dia eram realizadas as consultas espirituais. Ao conversar com um dos dirigentes do centro, ela foi informada que aquele era o dia dos passes e que as consultas eram feitas às quintas-feiras; foi recomendado, entretanto, que ela ficasse, participasse da oração e tomasse o passe, uma vez que este também é um componente importante de qualquer tratamento espiritual. O passe, de acordo com a dona de casa, ocorreu nos moldes tradicionais do espiritismo. Os presentes se sentaram em cadeiras numa sala e lhes foram distribuídas senhas numéricas de acordo com a ordem de chegada. Um dirigente fez uma oração, acompanhada de uma fala evangelizadora. Logo em seguida, as pessoas começaram a ser chamadas de acordo com as senhas para uma sala separada em que recebiam, privadamente, o passe de um médium colaborador do centro. Trata-se, portanto, da já bem documentada prática espírita de realizar, por meio da imposição de mãos, a manipulação, purificação e transmissão de fluidos energéticos para a pessoa que necessita dessa energia benéfica.

Discuti as características do passe de forma detida em outro lugar (Santos Barbosa 2018:59-68), mas é preciso retomar aqui alguns pontos dessa prática. O passe opera a magnetização do fluído universal, transformando-o num "bálsamo", termo muito utilizado pelos espíritas para descrever energias com capacidade de cura e recuperação. Ao entrar no corpo do receptor, o fluído magnetizado proporciona uma espécie de redução da entropia energética no corpo e na alma, além de purificar os canais de fluxo energético. Assim como o sangue flui pelo corpo transportando oxigênio e demais componentes para o bom funcionamento dos sistemas fisiológicos, o espírito também possui canais em que fluem correntes energéticas necessárias para a vida e para a manutenção da relação entre corpo e alma. Energias impuras são tidas pelos espíritas como mais densas e próximas da matéria, chegando a ter a capacidade de bloquear o fluxo energético do sistema espiritual ou mesmo comprometer seu funcionamento de um modo geral. Esse comprometimento pode ocasionar desde problemas espirituais até

7 Vale notar que a própria alcunha de "Casa de Caridade", no contexto espírita, evoca as Casas de Misericórdia, instituições que emulam elementos das irmandades católicas para a prática da caridade cristã. Tais instituições desempenharam e ainda desempenham um papel fundamental na oferta de serviços de saúde e assistência à população. Para algumas análises históricas desse fenômeno que remonta ao período colonial do Brasil e do Império Português, ver Mesgravis (1976) e Quiroga (2010). 
doenças físicas propriamente $\operatorname{ditas}^{8}$, o que torna o passe um componente indispensável da profilaxia e do tratamento que o espiritismo promove para corpo, mente e alma.

Ao fim do passe, os dirigentes do centro pediram que Dona Maria voltasse na noite de quintafeira, quando um médium (incorporando um espírito médico) realizaria uma consulta e analisaria suas dores nas pernas. Na quinta-feira seguinte, o procedimento na Estrada de Luz foi basicamente o mesmo. As pessoas chegaram, em número maior do que na noite de terça-feira, e se sentaram na sala, recebendo senhas de atendimento individual. Sem que houvesse fala ou algo análogo às costumeiras palestras realizadas na maioria dos centros espíritas, as pessoas começaram a ser chamadas para o cômodo em que as consultas eram realizadas. Quando chegou sua vez, Dona Maria entrou na pequena sala e o médium pediu para que ela se deitasse numa espécie de maca. $\mathrm{O}$ médium incorporava um espírito que se apresentou como "Doutor José", mas a identidade do médico espiritual não foi tema de nenhuma apresentação mais completa. Ao contrário dos espíritos quase míticos que pontuam as biografias de médiuns (como o mineiro José Arigó) e cujas histórias de vida frequentemente trazem à tona elaborações históricas e alguma dimensão de alteridade ${ }^{9}$, o médico espiritual que atendeu Dona Maria não comentou nada sobre suas encarnações passadas nem sobre sua experiência de prática médica neste ou no outro mundo.

No consultório improvisado havia também vários auxiliadores, responsáveis pela manutenção vibratória do ambiente através de passes e orações durante toda a consulta. Assim que Dona Maria deitou-se sobre a maca, o médium se aproximou e começou a fazer movimentos com as mãos sobre todo o corpo da dona de casa, como se realizasse passes localizados em cada membro e órgão. Esse procedimento durou alguns minutos, acompanhado das orações e passes realizados pelos auxiliadores. Durante esse tempo, Dona Maria permaneceu concentrada e em oração, tal como havia sido orientada pelos condutores da sessão. Logo em seguida veio o diagnóstico: a idosa sofria de "friagem nos ossos" ou, como o espírito buscou esclarecer, reumatismo. Essa constatação foi transmitida aos auxiliares com a presença de Dona Maria, assim como o tratamento sugerido: escalda-pés (uma técnica tradicional que consiste na submersão dos pés e tornozelos em água morna ou quente visando o relaxamento muscular e alívio das dores) e continuação tanto do tratamento médico convencional quanto do espiritual, havendo a necessidade de continuar visitando a Casa de Caridade para novas consultas e acompanhamento. A fala do médico espiritual foi rápida e direta, provavelmente para que outra pessoa pudesse entrar logo em seguida e garantir o máximo de atendimentos na noite. Dona Maria saiu da sala e aguardou pelo fim dos atendimentos, quando foi realizada uma oração de encerramento.

\footnotetext{
8 Embora não seja possível dizer que os espíritas sempre apontem uma causa espiritual para justificar uma doença, pude observar com grande frequência esse tipo de argumento para traçar as origens de problemas fisiológicos, emocionais e psicológicos de uma pessoa, o passe sempre constituindo a resposta básica para o início do processo de cura.

9 Alteridade histórica, no caso dos médicos cujas encarnações haviam se dado em épocas passadas, ou mesmo geográfica, como nos muitos casos documentados em que os espíritos eram médicos estrangeiros, especialmente alemães. O Dr. Adolf Fritz, conhecido espírito que operava pelas mãos de José Arigó (e posteriormente de outros médiuns que alegavam incorporá-lo), chegou a revelar sua história de vida numa entrevista através de Arigó. Nascido na Alemanha em algum momento do século XIX, Fritz mudou-se para a Polônia aos quatro anos por conta do estado de saúde de seu pai, que sofria de asma. Após a morte prematura dos genitores, o jovem foi obrigado a trabalhar e estudava medicina no pouco tempo livre que dispunha, chegando à universidade através de esforço e mérito próprios. Pouco antes de se graduar, um militar de alta patente chegou ao seu consultório em busca de ajuda médica para a filha que estava à beira da morte. $\mathrm{O}$ jovem médico não foi capaz de salvá-la e, por conta disso, acabou responsabilizado pela morte da garota. Na prisão, Fritz sofreu tortura e suportou grandes sofrimentos, conseguindo fugir para a Estônia, onde viveu de 1914 até sua morte em 1918.
} 
Dona Maria acabou não voltando à Casa de Caridade até o momento de escrita deste artigo, mas reconheceu que deveria e planeja estabelecer em breve uma agenda regular de participação nas sessões. Esse sentimento de que ela deveria, de fato, retornar era intensificado pela constatação de que as dores nas pernas haviam realmente diminuído desde a consulta espiritual, embora o problema ainda persistisse. A prática regular de escalda-pés também se mostrava eficaz em proporcionar relaxamento e sensação de alívio nos dias em que as dores atacavam com maior intensidade, apesar da dona de casa reconhecer que se trata de uma medida paliativa e não de um tratamento propriamente dito. Além disso, Dona Maria se mostrava inclinada a reconhecer a eficácia dos tratamentos espirituais por conta de uma experiência passada em que se viu livre de alguns problemas de saúde graças a uma cirurgia espiritual realizada num centro de outra cidade. No geral, a experiência de tratamento espiritual foi encarada como eficaz e todo o processo foi capaz de produzir na doente uma experiência de recuperação, ainda que parcial. A ideia de que a cura não é alcançada imediatamente, mas através de um tratamento processual e em conjunto com a medicina convencional, é um componente importante dessa eficácia, dado que Dona Maria sempre expressou uma desconfiança diante das curas miraculosas noticiadas na mídia - especialmente nos contextos neopentecostais e muitas vezes associadas ao exorcismo. Um tratamento mais "pés no chão" e "realista", portanto, lhe pareceu mais confiável e "verdadeiro".

\section{Concepções de doença e possibilidades da agência espiritual}

A narrativa de Dona Maria é ilustrativa de duas tensões importantes no interior da noção de cura espiritual tal como desenvolvida pelo espiritismo. Em primeiro lugar, a histórica tensão entre medicina convencional e medicina espírita, uma oposição que divide o próprio movimento kardecista acerca da natureza das mazelas do corpo e da alma, além de implicar diretamente no modo como o espiritismo constitui e legitima sua identidade como religião. Em segundo lugar, a oposição entre natureza/materialidade e religião/espiritualidade, que encontra no kardecismo uma configuração bastante específica. O espiritismo enfrenta ambiguidades no que diz respeito ao modo como identifica e trata problemas de saúde, com médiuns e espíritos priorizando ora questões (e disposições) do corpo físico ora problemas relacionados à alma e ao processo de evolução espiritual que constitui a base da doutrina espírita. Ambas as tensões se materializam na experiência concreta da pessoa que busca o tratamento oferecido pelo centro espírita. Em outras palavras, tais problemas podem ser pensados a partir da experiência corporificada (tanto em termos do corpo físico quanto do corpo espiritual) engendrada nesses processos de consulta, tratamento e cura espiritual.

O estudo da cura espiritual permite enfocar os corpos em sua dupla dimensão ontológica (material e espiritual), possibilitando a dissolução momentânea dessa separação que é um reflexo de outras dualidades caras ao pensamento científico (mente e corpo, sujeito e objeto etc.). Esta reflexão, portanto, está alinhada com os trabalhos de Thomas Csordas (1994; 2008) sobre a fenomenologia da cura em contextos religiosos: 
Ao dirigir o seu foco para a experiência corpórea, Thomas Csordas defende que a abordagem da corporeidade está para além da representação e do discurso, sem, contudo, deixar de incluir essas dimensões. Essa é a pedra de toque da sua abordagem do corpo, que não é mais nem o corpo como mero instrumento, corpo significado, nem o corpo como lugar de inscrição (para fazermos uso da metáfora textualista) da cultura, mas é o corpo fenomênico, o corpo como lócus da cultura, meio de sua experimentação do "fazer-se humano" em suas múltiplas possibilidades. (Steil e Murillo 2008:11).

Ao conferir importância à experiência corporificada do suplicante, essa abordagem também possibilita uma aproximação com a proposta de Diana Espírito Santo e Ruy Blanes (2014) para uma antropologia da agência de entidades intangíveis. Um posicionamento desse tipo implica em ir além das formulações ideológicas e doutrinárias, visando traçar as condições pelas quais tais entidades produzem efeitos no mundo, explorando também as dimensões narrativas que possibilitam seu reconhecimento e legitimação. No caso etnográfico em questão, que tipos de procedimentos e transformações possibilitam a eficácia da agência espiritual em direção à cura? Como esse quadro de experiências heterogêneas é capaz de articular disposições pessoais e coletivas que rivalizam e se articulam com o conhecimento médico convencional? Mais do que isso, como a experiência do tratamento espiritual, ao produzir sua eficácia, engendra também um entendimento do mundo e da natureza que não se opõe, mas engloba, a ciência secular?

Para responder a essas questões, minha proposta é começar justamente da cosmologia e do que poderíamos chamar de "ideologia" religiosa. Quando lidamos com fenômenos de cura e tratamento de aflições dos mais diferentes tipos, encontramos diferentes narrativas que disputam e se articulam na busca de legitimação. A própria natureza da aflição, conforme demonstra o caso de Dona Maria, é muitas vezes incerta, tanto pela ótica da medicina convencional quanto do tratamento religioso. Com efeito, o sofrimento físico e espiritual propõe um difícil dilema para as práticas terapêuticas espíritas. Marcelo Camurça (2016) identifica esse dilema na caracterização moral da doença no espiritismo:

Segundo a Doutrina Espírita, grosso modo, podemos situar as causas das doenças em dois eixos: 1) A doença ligada ao processo de desenvolvimento espiritual do indivíduo, expressando-se como resultado de situações vividas em "existências ou encarnações anteriores"; 2) A doença como produto de interferência de espíritos inferiores que dominam corpos e mentes de indivíduos vulneráveis a esta influência. Dá-se a este fenômeno, o nome de obsessão. (Camurça 2016:231).

De um ponto de vista doutrinário (e localizar essa concepção é um passo fundamental), a doença pode ser entendida como um reflexo cármico sobre o corpo/espírito de ações passadas nesta ou em outra encarnação. A "lei de causa e efeito" delineada por Allan Kardec opera como um poderoso organizador de experiências na medida em que confere um teor de determinismo divino (Camurça 2016:232) aos sofrimentos e problemas de ordem fisiológica e psicológica. Uma doença pode ser, por exemplo, o efeito de alguma ação terrível cometida numa existência anterior, isto é, um carma a ser expiado e uma experiência pela qual a pessoa merece passar.

Por outro lado, a doença também pode se configurar como uma investida de espíritos inferiores sobre a pessoa encarnada em decorrência de desequilíbrios na faixa vibratória desta última. Os 
espíritas chamam de "faixa vibratória" o nível energético evolutivo em que a pessoa se coloca através de suas ações e pensamentos, algo próximo da ideia de sintonia nas frequências de rádio. Uma pessoa que ocupe sua mente com pensamentos moralmente elevados e ações caridosas é capaz de alcançar faixas evolutivas mais altas e, por conta disso, se colocar sob a agência de espíritos evoluídos e guias benevolentes que a auxiliem em seu processo de melhoramento espiritual. Quando ocorre o inverso e a pessoa mergulha em pensamentos e atitudes maliciosas e moralmente condenáveis, seu espírito vibra em faixas inferiores e se coloca em contato com outros espíritos, pouco evoluídos. A partir disso, pode ocorrer o que os espíritas chamam de obsessão, isto é, o ato de um espírito inferior se "prender" a um encarnado de modo a influenciar suas escolhas, roubar energias, fazer o mal e causar danos à saúde física e mental da vítima ${ }^{10}$. Passa a ser, então, necessária a intervenção de outros espíritos e/ou médiuns para que o obsessor seja convencido a deixar a vítima em paz. Esta também deve buscar melhorar seus pensamentos e ações para evitar a ocorrência de novos casos de obsessão, geralmente através do estudo do espiritismo e da prática da caridade ${ }^{11}$.

O quadro formado pela doutrina espírita constitui uma retórica que se faz presente em qualquer discurso de cura nessa religião. A cura, segundo Csordas (2008, p. 50), depende de um discurso convincente que "transforma as condições fenomenológicas sob as quais o paciente existe e experiencia sofrimento ou aflição". O aspecto retórico da cura, portanto, direciona a atenção do paciente para determinadas ações e práticas ou coloca elementos habituais da experiência sob uma nova luz que produz novos significados. O autor chega a falar na construção de um "novo mundo fenomenológico" por meio dessa experiência, que transporta o paciente para um estado dissimilar ao estado de "pré-doença" e de "doença". Mostrar como essa nova realidade se constitui é uma das tarefas do projeto analítico de Csordas. Os fenômenos chamados pelo autor de "processos endógenos" são parte importante de como essa realidade se atualiza na experiência:

$\mathrm{Na}$ medida em que os processos endógenos ocorrem em níveis fisiológicos e intrapsíquicos, e a retórica age tanto no nível social da persuasão e influência interpessoal quanto no nível cultural dos significados, símbolos e estilos de argumento, a experiência da cura é uma experiência de totalidade. (Csordas 2002:25) ${ }^{12}$.

O caso espírita tem a particularidade de mobilizar tanto um discurso doutrinário/institucional de que os sofrimentos pelos quais uma pessoa passa na vida atual são frutos de suas próprias ações passadas (algo que deve ser "pago" e de que o paciente não pode escapar) quanto uma visão que integra espiritismo e catolicismo popular e que expressa a possibilidade de intervenção de agentes espirituais

10 Existem também casos de obsessão em que a vítima não é diretamente responsável ou ainda em que o espírito obsessor não tem plena consciência de suas ações. Um exemplo emblemático desses casos é quando a morte de um parente ou cônjuge leva o espírito agora desencarnado a obsediar alguma pessoa ainda viva por quem nutria muito afeto. A intenção do espírito, nesses casos, é muitas vezes a de tentar ajudar ou apenas ficar ao lado da vítima, mas sua ignorância e fixação acaba por causar danos a esta última.

11 Discussões sobre o processo de desobsessão podem ser encontradas em Cavalcanti (1983), Lewgoy (2000) e Santos Barbosa (2018). 12 Optei por traduzir eu mesmo este trecho porque na tradução oficial, publicada pela Editora da UFRGS, a relação que o autor busca estabelecer aparece um pouco obscurecida: "A experiência de cura é uma experiência de totalidade até onde os processos endógenos ocorrem em níveis fisiológicos e intrapsíquicos, e a retórica age tanto no nível social de persuasão e influência interpessoal quanto no nível cultural de significados, símbolos e estilos de argumentos." (Csordas 2008:51). O problema está no uso da expressão "até onde" para traduzir "insofar as". 
para amenizar os problemas e dores causados pelas dívidas cármicas ${ }^{13}$. O dilema foi notado por Camurça (2016:231), ao afirmar que o espiritismo brasileiro coloca, "de um lado, a ênfase numa ascese ética e espiritual diante da provação da enfermidade sugerida numa interpretação doutrinária e de outro, a prática costumeira das cirurgias espirituais e todo tipo de receituário usado como recurso terapêutico (passes, ingestão de água fluidificada etc.)." O resultado, em termos gerais, é uma definição ambígua da doença como algo que pode ser tanto uma provação pela qual a pessoa tem de passar nesta encarnação (como parte de seu processo evolutivo inescapável) quanto o resultado da ação de espíritos mal-intencionados, problemas no nível vibratório ou mesmo mazelas sem relação com o mundo espiritual (passível de intervenção por parte de agentes espirituais superiores). Essa ambiguidade faz toda a diferença quando a religião deve tomar uma posição quanto à possibilidade de tratamentos e cura espiritual.

O posicionamento institucional do espiritismo acabou envolto nesse dilema. Historicamente, a religião enfrentou acusações de charlatanismo e de prática ilegal da medicina (especialmente homeopatia e receitismo) ao ponto de precisar redefinir sua postura em direção a uma ênfase mais religiosa do que científica (Giumbelli 1997b; Arribas 2010). No século XX, já tendo se consolidado como parte do quadro religioso brasileiro, o espiritismo viu um aumento no número de médiuns que incorporavam espíritos de médicos e praticavam as chamadas cirurgias espirituais. Alguns realizavam, de fato, incisões e outras intervenções no corpo, atraindo a condenação de associações médicas e órgãos sanitários; outros realizavam os procedimentos num nível puramente espiritual, sem a necessidade de operar no corpo físico. De toda forma, médiuns como Zé Arigó e João de Deus colocaram o espiritismo nas manchetes nacionais e internacionais e nas discussões sobre a complexa relação entre religião e medicina (Souza 2014). Entretanto, os laços entre esses médiuns e as instituições espíritas, especialmente a Federação Espírita Brasileira (FEB), são quase sempre tênues e muitos deles, apesar de mobilizarem a categoria kardecismo, buscam estabelecer uma relação de independência com as federações e uniões. Figuras importantes do espiritismo, como Chico Xavier e Divaldo Franco, sempre mantiveram certa distância desse tipo de prática mediúnica e, embora tenham destacado o caráter caridoso das iniciativas, expressaram preocupação com a possível conversão de centros espíritas em hospitais (Jácome 1999:174).

Toda essa configuração tem impactos importantes nas experiências concretas de práticas terapêuticas no espiritismo. A questão central é apreender como as pessoas que buscam esses tratamentos encaram sua natureza espiritual em relação ao par corpo/alma e à medicina convencional e como essas dimensões se integram à experiência de buscar a cura por tais meios. O primeiro ponto a se notar é que a Casa de Caridade que atendeu Dona Maria não realiza cirurgias espirituais, atendo-se apenas ao que os dirigentes chamam de "consulta e tratamento espiritual". Essa característica implica num alinhamento mais próximo à postura institucional do "espiritismo da FEB", limitando a extensão dos procedimentos e técnicas empregados nas sessões. Consequentemente, a retórica observada na Casa de Caridade matizava a eficácia do tratamento espiritual com frequentes lembretes de que o tratamen-

13 Lewgoy (2000; 2004) e Stoll (2003) ofereceram, a partir de perspectivas diferentes, análises sobre essa dualidade no espiritismo entre um discurso doutrinário mais rígido e próximo dos escritos de Kardec e uma leitura embebida em valores do catolicismo popular, enfatizando a intervenção espiritual e a compaixão perante o sofrimento humano. Lewgoy (2004) identificou esses dois modelos como centrados, respectivamente, nas noções de "dívida" e "dádiva", o primeiro (ilustrado por Allan Kardec) estaria centrado no princípio quase mecânico do carma e da lei de causa e efeito, ao passo que o segundo (representado pela obra e vida de Chico Xavier) mobilizaria a agência individual e dos espíritos para flexibilizar tais mecanismos morais. 
to médico convencional não deveria jamais ser abandonado. As consultas, passes e diagnósticos ali produzidos deveriam ser tomados como complementos, como abordagens que se juntam aos esforços seculares em direção à cura, nunca como substitutos ou mesmo como soluções autônomas.

Há nesse discurso uma interessante articulação entre ciência e religião que contribui para a eficácia dos procedimentos terapêuticos. Ao não tomar o tratamento espiritual como um substituto da medicina convencional, o espiritismo coloca as duas modalidades de cura em continuidade. Com efeito, boa parte do movimento espírita (incluindo as associações de médicos espíritas) entende que a única razão para que a medicina secular não empregue conhecimentos kardecistas em sua prática é a limitação do próprio conhecimento humano. A tendência, afirmam os espíritas, é que a ciência avance para a comprovação da eficácia dos métodos espirituais e da importância do bem-estar espiritual para a saúde fisiológica. Muitos interlocutores chegavam a me dizer que em pouco tempo o espiritismo seria ensinado nas universidades. Por outro lado, o próprio procedimento de consulta, diagnóstico e tratamento mediúnico espelha a prática médica convencional, incluindo a ideia de que a cura não se dá por uma ruptura da experiência da doença a partir da intervenção do sobrenatural, mas de um processo rigoroso e controlado de mudanças de hábitos, medicamentos (materiais ou espirituais) e a própria capacidade regenerativa do corpo/alma. Esse processo deve ser conduzido tanto numa dimensão material quanto espiritual, dado que o ser encarnado é formado por uma unidade holística que reúne as duas naturezas.

\section{Entre Ciência e Milagre}

A partir desse quadro, chamo atenção para uma fala dos condutores da consulta à Dona Maria, destacando que ali não se fazia milagres, mas buscavam tratar os problemas do corpo e da alma dentro das possibilidades físicas e evolutivas dos pacientes. A contraposição entre o tratamento espiritual e a noção de milagre é particularmente ilustrativa. Uma definição da noção de milagre é proposta por Reesink a partir de sua pesquisa sobre catolicismo e aparições marianas:

Podemos avançar, então, com uma primeira definição do milagre como a interferência positiva do sobrenatural no natural, como a quebra da ordinariedade, a invasão do profano pelo sagrado, um momento de "crise" no mundo cotidiano e "prático" dos indivíduos, sendo também a realização daquilo que está além das forças do natural, ou seja, como ruptura e transgressão da ordem natural. (Reesink 2005:270).

A autora complementa essa definição ao propor a existência de um "regime de milagre" no qual operam relações de reciprocidade, sacralização, fé e prova, aliança e comunicação entre fiéis e Nossa Senhora (Reesink 2005:279). O que é interessante de se destacar a partir da noção de milagre - e podemos observar esse quadro tanto no catolicismo quanto nos contextos pentecostais (Rabelo et al. 1998) - é a importância de definir a descontinuidade envolvida na agência do sagrado em oposição ao secular ou mundano; faz-se necessário, parafraseando Reesink, passar de um regime para outro, alterando linguagens, experiências, imaginações e atitudes. 
Reesink encontrou em campo uma noção de milagre marcada pela transgressão da ordem natural. Entretanto, essa concepção nem sempre foi prevalente no catolicismo. O trabalho historiográfico de Benedicta Ward (1987) oferece um panorama das mudanças que marcaram a noção de milagre na Idade Média. A autora demonstra que a primeira grande teoria dos milagres, elaborada em quatro tratados de Santo Agostinho (De Genesi ad Litteram, De Trinitate, De Utilitate Credendi, e De Civitate $D e i)$ apenas concebia a existência de um único milagre: a Criação. A principal consequência dessa ideia é a imbricação entre ordem natural e poder divino:

Toda a criação era, portanto, "natural" e "milagrosa". [...] Os eventos do dia-a-dia, o nascimento dos homens, o crescimento das plantas, a chuva, são todos "milagres cotidianos", sinais do misterioso poder criativo de Deus operando no universo. (Ward 1987:3, tradução minha).

Agostinho afirma, entretanto, que os homens tenderiam a se tornar acostumados a tais milagres cotidianos, necessitando ser provocados por manifestações mais incomuns do poder de Deus. O ponto fundamental é que Agostinho defende que mesmo tais eventos extraordinários, aparentemente contrários à natureza das coisas e do mundo, seriam inerentes à ordem da Criação:

Para Agostinho, os mecanismos dos milagres eram claros. Eles eram atos maravilhosos de Deus vistos como eventos neste mundo, não em oposição à natureza, mas expondo o trabalho oculto de Deus dentro de uma natureza que era plena de potencial milagroso. (Ward 1987:3, tradução minha).

Milagres, na teologia de Agostinho, não se davam contra naturam, mas praeter ou supra naturam. Essa foi a visão prevalente no catolicismo até o século XI, quando Anselmo de Cantuária, trabalhando a partir das categorias de Agostinho, traçou distinções fundamentais na noção de milagre. As mirabilia, isto é, eventos maravilhosos capazes de despertar o espanto e adoração dos homens, se distinguiriam dos acontecimentos naturais e/ou causados pela ação humana por envolverem uma intervenção direta da agência de Deus sobre a ordem das coisas (a travessia do Mar Vermelho, a transformação de água em vinho e as curas e ressurreições operadas por Jesus, para citar alguns exemplos):

Milagres são atos de Deus não submetidos às leis da natureza ou à forma pela qual o homem age usualmente na natureza, enquanto natureza e humanidade são elas próprias submetidas ao poder "milagroso" de Deus: "O milagroso não está sujeito aos outros dois ou suas leis, mas os governa livremente". (Ward 1987:5, tradução minha).

Essa posição teológica foi desenvolvida por Pierre Abélard em seu comentário ao livro de Gênesis, propondo uma definição de milagre como eventos contra ou supranaturais causados pela intervenção direta de Deus. Essa discussão impactou radicalmente o modo como a natureza e a ordem divina eram percebidas. Pela primeira vez, foi operada uma cisão entre eventos englobados pela onipotência e agência divina (milagres) e eventos que, apesar de também estarem contidos na Criação, seguem a ordem natural das coisas (natureza). A restrição da abrangência da noção de milagre, agora limitada aos eventos realmente incomuns e maravilhosos, permitiu a constituição de um domínio da Criação que 
deveria ser observado por suas próprias dinâmicas e mecânicas, um empreendimento que ganhou força com o (re)aparecimento dos trabalhos de Aristóteles sobre física e seus comentadores árabes:

Adelardo [de Bath, filósofo do século XII] respondeu que o modo apropriado para se descobrir a 'causa e origem' do trovão era examinar suas causas imediatas nas correntes de ar. Uma tempestade se tornara meramente uma tempestade, em vez de uma mensagem de Deus. (Ward 1987:6, tradução minha).

Nesse sentido, as discussões sobre milagres nos séculos XI e XII permitiram que a filosofia se debruçasse sobre o funcionamento da ordem natural enquanto um domínio autônomo (embora ainda submetido à Criação) e separado dos eventos maravilhosos e sobrenaturais que constituíam os milagres. A natureza começava a ganhar a autonomia que viria a possibilitar o surgimento da ciência secular plenamente separada da religião (e eventualmente lhe fazendo oposição).

Meu objetivo em recuperar esse percurso histórico das noções de milagre e natureza é estabelecer uma analogia entre tais concepções da articulação entre religião e ciência (ou natureza, enquanto objeto de observação e intervenção humana) e o que observamos na experiência de cura no kardecismo. Este último também comporta um grau de aproximação entre a ordem natural e o sagrado em seus procedimentos terapêuticos - o poder da manipulação energética, especialmente por via do passe, é um exemplo -, entretanto é notável como a eficácia retórica dessas formas de tratamento se dão a partir da afirmação da continuidade entre o natural/material e o espiritual. O espírito que examinou Dona Maria no exemplo etnográfico realizou um procedimento médico convencional, possibilitado pelo saber médico adquirido quando encarnado. A condição de espírito e o contexto religioso que envolve sua atuação servem como amplificadores de um conhecimento que é natural, científico (na perspectiva dos espíritas) e que pode ser controlado. Mesmo a manipulação energética, a terapia com fluídos e as próprias cirurgias espirituais mais performáticas são, no limite, manipulações de elementos que pertencem ao domínio da natureza e da ciência. A alcunha de "religiosos" ou "místicos" para descrever tais procedimentos são resultantes do acesso limitado que os encarnados possuem da natureza e do próprio mundo espiritual. $\mathrm{O}$ fato de o conhecimento médico adquirido em vida ser aplicável e passível de desenvolvimento no mundo espiritual é um exemplo dessa lógica. A continuidade existente entre a ciência secular e o universo espiritual permite que o kardecismo articule as duas dimensões numa relação de englobamento em que a "ciência espírita" aparece como uma categoria ampla o suficiente para abarcar tanto a medicina convencional quanto os tratamentos religiosos.

A interação entre discursos científicos religiosos se encontra no coração do processo de formação do espiritismo (Aubrée e Laplantine 1990; Arribas 2010; Giumbelli 1997b; Vasconcelos 2003; entre outros). Mas é interessante notar que o fluxo entre ciência e religião no século XIX foi, em muitas ocasiões, de mão dupla. Stoll (2003:34) aponta como "vários cientistas ingleses, do círculo de relações de Darwin por exemplo, aderiram à vertente anglo-saxônica do movimento espiritualista”, ao mesmo tempo em que "algumas das doutrinas religiosas surgidas na Europa à época passaram a reivindicar o estatuto de ciência”. O codificador do espiritismo, o pedagogo francês Hippolyte Léon Denizard Rivail (1804-1869), que adotou o nome Allan Kardec na assinatura das obras espíritas, expressou essa atmos- 
fera que prevalecia nos círculos esclarecidos da Europa oitocentista ao descrever o caráter experimental e objetivo dos fenômenos e estudos que deram origem à sua obra:

Foi aí que fiz os meus primeiros estudos sérios em Espiritismo, menos ainda por efeito de revelações que por observação. Apliquei a essa nova ciência, como até então o tinha feito, o método da experimentação; nunca formulei teorias preconcebidas; observava atentamente, comparava, deduzia as consequências; dos efeitos procurava remontar às causas pela dedução, pelo encadeamento lógico dos fatos, não admitindo como válida uma explicação, senão quando ela podia resolver todas as dificuldades da questão. [...] Compreendi, desde o princípio, a gravidade da exploração que ia empreender. Entrevi nesses fenômenos a chave do problema tão obscuro e tão controvertido do passado e do futuro, a solução do que havia procurado toda a minha vida; era, em uma palavra, uma completa revolução nas ideias e nas crenças; preciso, portanto, se fazia agir com circunspeção, e não levianamente; ser positivista, e não idealista, para me não deixar arrastar pelas ilusões. (Kardec 2013:13).

A austera visão científica de Kardec, entretanto, foi colocada em segundo plano nas leituras brasileiras do espiritismo no final do século XIX. As transformações, algumas delas radicais, do espiritismo no Brasil é tema central do trabalho de Arribas (2010), mas desejo ressaltar aqui apenas um ponto específico desse debate: a tensão presente até hoje entre vertentes religiosas e científicas no interior do espiritismo. A questão remonta aos confrontos intelectuais ocorridos no interior dos grupos espíritas e, posteriormente, da Federação Espírita Brasileira (FEB), assim como ao processo de perseguição e ameaça jurídica de que o espiritismo (e diversas outras religióes, destacadamente as de matriz afro-brasileira) foram alvo durante a Primeira República (Giumbelli 1997b). O ponto nodal do processo pode ser localizado na trajetória de Bezerra de Menezes, médico, político e figura central no espiritismo brasileiro que, em 1888, assumiu a presidência da (FEB) e buscou unificar as vertentes conflitantes da federação, que se dividiam entre religiosos, científicos e filosóficos (ou místicos), com suas respectivas ênfases. Bezerra de Menezes possuía uma relação próxima com o catolicismo, decorrente da criação numa família e contexto social atrelados ao "catolicismo popular". Esse alinhamento fez-se sentir principalmente em sua segunda presidência na FEB, em 1895, quando abandonou a tentativa de conciliação entre as vertentes e partiu para uma representação mais direta dos religiosos.

Por questões de espaço, não entrarei no processo de transformação que a trajetória e produção mediúnica de Chico Xavier realizou no espiritismo ${ }^{14}$, bastando afirmar que ele também aprofundou uma ênfase religiosa que reduziu a centralidade experimental e positivista que Kardec conferia ao seu método de compreensão dos fenômenos espirituais. É nesse sentido que o espiritismo, como objeto de reflexão, permite

relativizar a tendência, de certo modo consolidada, de tratar religião e ciência como campos de conhecimento autônomos e/ou excludentes. [...] [E]stes sistemas de conhecimento mantém relações intensas que são, ao mesmo tempo, de aproximação e distanciamento; de confronto e influência; de apropriação e reinterpretação inesperadas. (Stoll 2003:35).

14 Para um trabalho minucioso sobre a questão, ver Lewgoy (2000; 2004). 
A discussão de João Vasconcelos (2003) aponta ainda que, durante boa parte do século XIX, um programa de verdade específico - o científico, fundado na ideia de "prova" como pilar epistemológico - se apresentava como o paradigma do conhecimento aceitável e legítimo, contexto que influenciou profundamente a definição do espiritismo como movimento:

Embora o próprio Kardec tenha deixado bem claro que a ciência espírita não era uma ciência como as outras, muitos dos seus seguidores ignoraram esta cautela e batalharam por um estatuto de paridade. Essa batalha, porém, foi perdida, e o Espiritismo ora ficou numa espécie de limbo entre a religião e a ciência, ora acabou por ser socialmente definido como uma religião. (Vasconcelos 2003:119).

O segundo caminho foi o trilhado pelo espiritismo no Brasil, especialmente durante a Primeira República, quando as práticas terapêuticas e receitistas da religião (que permaneciam como um reduto de ênfase parcialmente científica ou que, pelo menos, lidavam com uma eficácia já englobada pela ciência médica) se chocaram com os estatutos e normas sanitaristas promovidos pelo Estado republicano no intuito de forçar a modernização da sociedade brasileira e a extinção de crendices e charlatanismos, tal como eram classificadas essas práticas ${ }^{15}$. A sobreposição de saberes, ou melhor, de diferentes regimes de conhecimento, colocou o espiritismo contra a medicina e levou ao seu enquadramento no código penal como uma prática de enganação, dado que, para o Estado, a promessa de eficácia da cura apenas era legítima quando provinda de um saber científico reconhecido como tal.

O espiritismo brasileiro, tanto por conta de processos de disputa e negociação de legitimidade quanto pelas trocas e diálogos com as demais religióes que formavam o panorama nacional (especialmente o catolicismo popular e a umbanda), se consolidou como um movimento religioso capaz de reivindicar a proteção legal que a Constituição concedia por meio da noção de liberdade religiosa. Ao longo do século XX, esse posicionamento permitiu um fluxo intenso de simbolismos e noções entre kardecismo e catolicismo popular, aproximando as duas modalidades de experiência do sagrado. Um dos resultados desse amálgama é uma configuração que ecoa elementos da teologia católica agostiniana, ou melhor, que não prevê cisões entre natureza (o mundo cotidiano) e agência divina/espiritual. Embora o espiritismo tenda a rejeitar a noção de milagre para descrever a intervenção dos espíritos, como fizeram os médiuns da Estrada de Luz, não há um grande espaço para a afirmação de uma ordem natural sobre a qual, ocasionalmente, se faz sentir as manifestações do sagrado. Toda a ordem cósmica é, ela própria, englobada pelas inexoráveis dinâmicas do mundo espiritual.

A principal implicação dessa cosmovisão é que o espiritismo possibilita que o sujeito experiencie um mundo atravessado constantemente pelo intenso fluxo de relações que articula o plano físico e o plano espiritual de forma mútua. As etnografias sobre o espiritismo são particularmente enfáticas ao discutir a centralidade dessa rede de interações entre encarnados e desencarnados que formam não um domínio apartado da vida cotidiana (o "sobrenatural" ou o "sagrado"), mas a própria lógica dessa realidade $^{16}$. É trivial para um kardecista a percepção de que espíritos atuam o tempo todo sobre o mundo de forma "institucionalizada" (o que a literatura espírita denomina Divina Providência). Do mesmo

15 Isso quando não se recorria à acusação de loucura, como aponta Giumbelli (1997a; 2008). 16 Minha própria pesquisa se dedicou a essa questão (Santos Barbosa 2018). 
modo, os kardecistas tomam como dado o princípio de que a lógica que rege os fenômenos "naturais" (desde o comportamento das moléculas até os eventos cósmicos) está inscrita na espiritualidade. A dimensão espiritual se mostra, portanto, como lógica englobante dentro da qual se imbricam aquilo que não conhecedores classificariam como fenômenos inconciliáveis (o sagrado e o natural/científico). É nesse sentido que a ciência é um discurso reivindicado pelo movimento espírita: se o conhecimento científico é o resultado da observação das dinâmicas que verdadeiramente constituem a realidade, não é surpreendente que os espíritas o entendam como inerentemente espiritual, dado que o próprio cosmos é um produto de mecânicas desse tipo. Ciência e religião aparecem como categorias turvas nesse modelo, justificando a posição de meus interlocutores de que não tardaria para que o espiritismo fosse ensinado nas universidades. Mas essa forma de apreender os fenômenos no mundo também tem impactos diretos em experiências que, como a busca pela cura, envolvem um conjunto de narrativas que disputam a legitimidade para agir e pensar sobre o corpo, a mente e o espírito.

Se retornarmos ao nível das experiências pelas quais passam os suplicantes no contexto kardecista, surge a oportunidade de discutir a articulação entre as ordens natural e espiritual na busca pela cura. Tomando a perspectiva de Dona Maria, ao chegar na Casa de Caridade, observamos que os espíritas buscam construir continuidades concretas entre a medicina e o tratamento mediúnico. Os visitantes são recebidos numa sala de espera e recebem senhas, emulando a estrutura de um consultório convencional. $\mathrm{O}$ médium incorpora o espírito de um especialista que procede ao exame, sem saber de antemão o problema a ser tratado. Esse detalhe é importante por levantar a possibilidade de erro no diagnóstico ou de eventuais dificuldades do médico espiritual em identificar a causa da aflição. Os próprios suplicantes se tornam cientes de que estão passando por um processo que não conta com a infalibilidade divina (o que o distingue do milagre), mas sim com o "trabalho voluntário" de um espírito benfeitor. Uma eventual cura, portanto, será devida à habilidade do médico, do médium e da eficácia do tratamento, em oposição à simples agência de um poder divino externo ao domínio da natureza. A experiência na Casa de Caridade guia os suplicantes pelas mesmas etapas que muitos deles já passaram nos consultórios seculares: criação de uma ficha com informações dos sintomas, consulta, exames, diagnóstico, tentativas de tratamento e acompanhamento. Os métodos são, de fato, heterogêneos: o médico espiritual recomenda passes, orações, mudanças alimentares e de hábitos, práticas de alívio dos sintomas e até mesmo o encaminhamento para instâncias médicas mais especializadas no campo secular. Poderíamos falar, assim, num duplo processo de naturalização das terapias religiosas e de espiritualização dos processos fisiológicos, resultando em experiências que desafiam definições muito estreitas desses universos discursivos.

Muitos dos suplicantes que buscam o tratamento espírita se encontram desiludidos com a eficácia dos métodos convencionais. O kardecismo lhes fornece uma experiência que emula a confiabilidade e sobriedade do método médico-científico ao mesmo tempo em que lança toda a experiência para o domínio superior ou englobante, que é o mundo espiritual. Toda a trajetória do paciente na Casa de Caridade é marcada por ambiguidades: a doença pode ser um efeito cármico, a influência de um espírito mal-intencionado ou uma mazela comum; o tratamento pode incidir sobre corpo, mente e alma; seus métodos são espirituais, mas sua eficácia se dá no domínio da natureza; a operação não 
ocorre sob o signo do mistério divino, mas da aplicação de princípios universais e "científicos", e por aí vai. O processo não exige do suplicante o salto de fé que atravessa o "regime de milagre", nem implica a necessidade de afastar-se do mundo em prol da purificação requerida pela agência do Espírito Santo, assim como não traça obrigações rituais que devem ser cumpridas. $O$ paciente precisa apenas ocupar a posição que lhe cabe: a de paciente. Ele deve se submeter a um saber que não lhe é estranho, mas que está num nível superior de eficácia e essa superioridade não resulta de uma qualidade externa ao mundo das dores e dos sofrimentos concretos, mas de uma compreensão mais profunda desses problemas, possibilitada pela agência dos espíritos ${ }^{17}$.

Ao questionar como esse tipo de processo religioso produz sua eficácia, podemos citar três tarefas centrais que a retórica da cura deve lograr, segundo Csordas:

1. Predisposição - dentro do contexto da comunidade primária de referência, o suplicante deve ser persuadido de que a cura é possível, que as alegações do grupo a esse respeito são coerentes e legítimas. 2. Empoderamento - o suplicante deve ser persuadido de que a terapia é eficaz - que ele está experienciando os efeitos curativos do poder espiritual.

3. Transformação - o suplicante deve ser persuadido a mudar - isto é, ele deve aceitar a transformação comportamental cognitiva/afetiva que constitui a cura dentro do sistema religioso. (Csordas 2008:53).

Analisando essas três tarefas no interior do sistema espírita, é possível apreender, em primeiro lugar, como a predisposição à cura se fortalece a partir da referência à medicina convencional. A afirmação da continuidade existente entre o tratamento que o suplicante muitas vezes já realiza fora do centro e as atividades mediúnicas permite que ambas as experiências se entrelacem e partilhem de uma única base de eficácia, que é a do conhecimento (humano ou espiritual) sobre a natureza do mundo e possíveis intervenções que se pode realizar nesse ambiente. $\mathrm{O}$ mesmo vale para a questão do empoderamento; o paciente percebe que a ida ao centro espírita e a experiência de tomar passes, beber água fluidificada e ouvir as sugestões do médico espiritual se junta às iniciativas que vem realizando por meio da medicina convencional, como os medicamentos, as sessões de terapia e a prática de exercícios. Dessa forma, a eventual falha de algum componente do tratamento não implica necessariamente na ineficácia do processo, mas em algum problema na conjunção entre essas atitudes e disposições.

A transformação envolve uma dinâmica retórica mais complexa. Do mesmo modo que a "demonologia carismática" no catolicismo pentecostal estudado por Csordas e seu consequente movimento de externalização (via exorcismo) articula "metáforas negativas do self” que são transformadas em "motivos positivos, alterando profundamente a maneira de os suplicantes lidarem com seus próprios padrões de cognição, afeto e comportamento" (2008: 69), o processo de consulta e tratamento espiritual também mobiliza reordenamentos no modo como o suplicante apreende (e vive) sua aflição. Um caso importante é o redirecionamento da atenção para uma autoavaliação moral, uma vez que o problema

17 O processo é, assim, bastante diverso do que descrevem as narrativas de curas milagrosas entre pentecostais e católicos citadas no trabalho de Singleton (2001). Vale notar também a diferença no modo como a experiência de cura e tratamento é construída e narrada nesses dois contextos religiosos. 
de saúde pode ser reflexo de atos repreensíveis em encarnações passadas. Nesse caso, o paciente deve se perguntar se está fazendo sua parte no processo de resgate das dívidas cármicas e se tem praticado a caridade e o estudo como formas de mitigar tais faltas. Uma reorientação de hábitos e atitudes pode ser necessária e isso é levado em conta tanto pelo suplicante quanto pelo médium que o atende. Por outro lado, a doença também pode resultar de alguma forma de obsessão, sendo necessária uma reorientação análoga para escapar da influência espiritual negativa, além do processo mediúnico de desobsessão. Por fim, a doença também pode não estar relacionada a nenhum desses fatores e ser apenas uma doença comum, requerendo a atuação da medicina convencional e o eventual auxílio de guias espirituais. De todo modo, o processo leva o suplicante a examinar e reposicionar sua experiência da doença dentro de um quadro mais amplo de questões espirituais e materiais. A partir dessa transformação, ele passa a encarar seu problema por perspectivas diferentes e em articulação com as dinâmicas cósmicas mais amplas, possibilitando novas formas de agência e tratamento.

\section{Considerações Finais}

Um elemento importante, que deve ser depreendido do caso etnográfico de Dona Maria e dos procedimentos terapêuticos no espiritismo, é a particularidade com que a experiência do suplicante produz a eficácia dos métodos. As tensões e ambiguidades citadas acima turvam importantes separações que se fazem presentes na maioria das religióes e dos casos de cura espiritual/milagrosa. A credibilidade e confiança externalizadas pelo espiritismo quando este se articula ao saber médico secular, expandindo seus significados e capacidades, garante que o suplicante passe de um regime material para um regime espiritual sem rupturas no nível dos fenômenos concretos que orientam a vida cotidiana. Mais do que isso, o espiritismo integra essas dimensões numa relação ampla de englobamento e que mobiliza tanto as limitações de agência - o tratamento sempre pode falhar, pois tanto o médico encarnado quanto o espírito são seres limitados, não são santos ou deuses - quanto a evidente superioridade moral e técnica do mundo espiritual. Essas tensões são sintetizadas na expressão "aqui não fazemos milagre", demarcando simultaneamente a proximidade com os significados e experiências que o suplicante já possui a partir dos tratamentos convencionais e também a relação com uma ordem superior de existência que não é externa ou oposta ao mundo vivido.

O procedimento de cura espiritual, nesse contexto, é instrumentalizado, processual e aberto; seu motor não é a lógica do milagre, mas das leis espirituais que regem a matéria e o espírito. Esse ponto mediano que ocupa os dois polos da relação confere credibilidade e eficácia na perspectiva das pessoas que buscam meios alternativos à medicina convencional sem precisar apelar a regimes muito extremos de experiência religiosa. Voltando à narrativa de Dona Maria, sua confiança na capacidade do médico espiritual era derivada justamente de sua qualidade enquanto especialista, cuja agência está sempre limitada ao campo das possibilidades concretas. Não lhe prometeram uma cura imediata (algo que no espiritismo é muito mais complicado do que nas demais religiões cristãs), mas apenas a tentativa de fazer o possível perante as circunstâncias. Agentes espirituais também são limitados pela ordem cósmica e o reconhecimento desses limites indica uma sinceridade que, para muitos suplicantes, não está pre- 
sente naqueles que "prometem céu e terra". O processo também foi fortalecido pelo papel que a própria Dona Maria teria de desempenhar: continuar frequentando os consultórios convencionais, pôr em prática as medidas terapêuticas sugeridas (o escalda pés) em conjunto com os medicamentos usuais e a participação regular nas sessões e consultas futuras - aprofundando o reordenamento da experiência dentro do próprio sistema religioso.

O espiritismo, desse modo, é cuidadoso com suas caracterizações da cura. A figura do milagre existe, mas sua mobilização geralmente ocorre no registro quase mítico dos Evangelhos e da biografia de Jesus, além de alguns casos de santos, relacionando essa notável capacidade de empregar o domínio espiritual para a transformação material ao altíssimo grau evolutivo desses personagens. Por outro lado, a própria história da religião está ligada a um elogio e incorporação do conhecimento e método científicos como forma de acessar tanto o mundo material quanto os fenômenos espirituais. Essa configuração é parcialmente responsável pelo posicionamento institucional do espiritismo, que desencoraja as intervenções espirituais mais drásticas sobre o corpo em nome da saúde. As terapias recomendadas são sempre orientadas pelo pragmatismo que emula a prática médica e pelos conteúdos morais que orientam a doutrina. O produto dessas articulações são experiências como a de Dona Maria, que afirmam a eficácia do tratamento tanto pela proximidade com o mundo espiritual quanto pela relação com as familiares passagens pela medicina convencional.

Allan Wine Santos Barbosa é doutorando no Programa de Pós-Graduação em Antropologia Social da Universidade Federal de São Carlos (UFSCar) e bolsista na Fundação de Amparo à pesquisa do estado de São Paulo (FAPESP), (processos $n^{\circ}$ 2015/22979-4 e 2017/20741-6). Agradeço à FAPESP pelo financiamento que possibilitou a realização deste trabalho.

\section{REFERÊNCIAS BIBLIOGRÁFICAS}

ARRIBAS, Celia da Graça. 2010. Afinal, espiritismo é religião? A doutrina espirita na formação da diversidade religiosa brasileira. São Paulo: Alameda.

AUBRÉE, Marion; LAPLANTINE, François. 1990. La table, le livre et les esprits: naissance, évolution et actualité du mouvement social spirite entre France et Brésil. Paris: J.C. Lattès.

CAMURÇA, Marcelo Ayres. 2016. "Entre o Carma e a Cura: Tensão Constitutiva do Espiritismo no Brasil”. PLURA - Revista de Estudos de Religião 7(1): 230-51.

CAVALCANTI, Maria Laura Viveiros de Castro. 1983. O Mundo Invisivel: cosmologia, sistema ritual e noção de pessoa no espiritismo. Rio de Janeiro: Zahar.

CSORDAS, Thomas. 1994. The Sacred Self: A Cultural Phenomenology of Charismatic Healing. Berkeley: University of California Press. .2002. Body, Meaning, Healing. New York: Palgrave Macmillan. 
2008. Corpo/Significado/Cura. Porto Alegre: UFRGS.

ESPÍRITO SANTO, Diana; BLANES, Ruy. 2014. "Introduction: On the Agency of Intangibles". In: The Social Life of Spirits, p. 1-32. Chicago: The University of Chicago Press.

GIUMBELLI, Emerson. 1997a. “Heresia, doença, crime ou religião: o espiritismo no discurso de médicos e cientistas sociais”. Revista de Antropologia 40(2):31-82.

. 1997b. O cuidado dos mortos: uma história da condenação e legitimação do espiritismo. Rio de Janeiro: Ministério da Justiça, Arquivo Nacional.

. 2008. "Kardec nos Trópicos”. Revista de História da Biblioteca Nacional, 33(3): 14-19.

JÁCOME, Óscar Junqueiro. 1999. A Doutrina põe Ordem na Desordem: O Espírito da Cura na 'Benzeção Espírita' da Associação Espírita Padre Antônio Vieira. Dissertação em Ciências da Religião, Juiz de Fora: Universidade Federal de Juiz de Fora.

KARDEC, Allan. 2013. O Que éo Espiritismo: Introdução ao conhecimento do mundo invisivel, pelas manifestações dos espiritos. Brasília: FEB.

LEWGOY, Bernardo. 2000. Os espiritas e as letras: um estudo antropológico sobre cultura escrita e oralidade no espiritismo kardecista. Doutorado em Antropologia Social, São Paulo: Universidade de São Paulo.

2004. O grande mediador: Chico Xavier e a cultura brasileira. Bauru: EDUSC: CNPq/Pronex. LUCCHETTI, Alessandra Lamas Granero. 2013. Descrição da terapia complementar religiosa em centros espiritas da cidade de São Paulo com ênfase na abordagem sobre problemas de saúde mental. Dissertação de Mestrado, São Paulo: Universidade de São Paulo.

MESGRAVIS, Laima. 1976. A Santa Casa de Misericórdia de São Paulo: Contribuições ao estudo da Assistência Social no Brasil. São Paulo: Conselho Estadual de Cultura.

MORAES, Ângela Teixeira de. 2017. “O discurso da saúde no espiritismo: Do magnetismo à autocura”. Religare: Revista do Programa de Pós-Graduação em Ciências das Religiōes da UFPB 14(1): 90-108.

QUIROGA, Ana Maria. 2010. “Assistência Social no Rio de Janeiro oitocentista: desqualificação dos atendidos, racismo científico e filantropia”. Texto apresentado no XIV Encontro Regional da Associação Nacional de História. Rio de Janeiro: Unirio.

RABELO, Miriam Cristina et al. 2002. "Comparando Experiências de Aflição e Tratamento no Candomblé, Pentecostalismo e Espiritismo”. Religião e Sociedade 22(1): 93-122.

REESINK, Mísia Lins. 2005. "Para uma Antropologia do Milagre: Nossa Senhora, seus devotos e o Regime de Milagre”. Caderno CRH 18(44): 267-80.

SANTOS BARBOSA, Allan Wine. 2018. Dádivas de Além-Túmulo: Circulação e Hierarquia no Espiritismo Kardecista. Dissertação de Mestrado em Antropologia Social, São Carlos: Universidade Federal de São Carlos.

SHANAFELT, Robert. 2004. "Magic, Miracle, and Marvels in Anthropology”. Ethnos 69(3): 317-40.

SINGLETON, Andrew. 2001. “'Your Faith Has Made You Well': The Role of Storytelling in the Experience of Miraculous Healing”. Review of Religious Research, 43(2): 121-38. 
SOUZA, André Ricardo de. 2014. "A Medicina do Além: Entre o Espiritualismo e o Espiritismo Kardecista”. Trabalho apresentado na 29a Reunião Brasileira de Antropologia em Natal - RN, 20. STEIL, Carlos. MURILLO, Luis Felipe. 2008. “Apresentação”. In: CSORDAS, Thomas. Corpo, significado, cura. Porto Alegre: UFRGS.

STOLL, Sandra Jacqueline. 2003. Espiritismo à Brasileira. São Paulo: EDUSP.

TONIOL, Rodrigo. 2014. "Integralidade, holismo e responsabilidade: Uma etnografia sobre a promoção de terapias alternativas/complementares no SUS”. In: FERREIRA, Jackeline; FLEISCHER, Soraya. Etnografias em serviços de saúde,. Rio de Janeiro: Editora Garamond.

.2015. "Espiritualidade que faz bem: Pesquisas, políticas públicas e práticas clínicas pela promoção da espiritualidade como saúde”. Sociedad y Religión, 43(XXV): 110-143.

VASCONCELOS, João. 2003. "Espíritos clandestinos: espiritismo, pesquisa psíquica e antropologia da religião entre 1850 e 1920”. Religião e Sociedade, 23(2): 92-126.

WARD, Benedicta. 1987. Miracles and the Medieval Mind: Theory, Record and Event 1000-1215. Aldershot: Wildwood House. 


\section{“AQUi A GENTE NÃO FAZ MILAGRE”: PARTICULARIDADES DO TRATAMENTO ESPIRITUAL DE DOENÇAS NO ESPIRITISMO KARDECISTA}

Resumo: Busco discutir neste artigo o processo de tratamento espiritual e cura oferecidos por um pequeno centro espírita de São Carlos, interior de São Paulo. A partir de um caso etnográfico, analiso as técnicas e discursos empregados pelos espíritas em relação ao conhecimento médico convencional. Discuto também como o tratamento espiritual não busca se opor à ciência médica secular, mas se constrói enquanto um desenvolvimento da, assim apreendida, limitação do conhecimento humano. A imbricação entre o contexto espírita e o conjunto de técnicas e procedimentos advindos da ciência médica produz uma situação em que o processo de cura é encarado pelos pacientes de forma diversa da noção de "milagre", presente em contextos católicos e pentecostais. O procedimento da cura espiritual implica num trânsito entre espiritualidade e materialidade, diferentemente da manifestação transcendental do sagrado que caracteriza o milagre. $O$ trabalho visa, portanto, oferecer uma contribuição etnográfica aos debates sobre a interface entre saúde e espiritualidade por meio de um enfoque nas formas pelas quais esse universo de significados e práticas se materializa na experiência dos frequentadores de um centro espírita.

Palavras-Chave: cura espiritual; espiritismo; mediunidade; milagre; saúde.

\section{“WE DON'T DO MIRACLES HERE": SPECIFICITIES OF SPIRITUAL HEALING IN KARDECIST SPIRITISM}

Abstract: In this article, I seek to discuss the process of spiritual treatment and healing offered by a small spiritist center of São Carlos, in the state of São Paulo. Starting from an ethnographic case, I analyze the techniques and discourses employed by spiritists in relation to conventional medical knowledge. I also discuss how spiritual treatment does not seek to oppose secular medical science but constructs itself as a development of the apprehended limitation of human knowledge. The imbrication between the spiritist context and the set of techniques and procedures derived from medical science produces a situation in which the healing process is viewed by patients in a manner different from the notion of "miracle" present in Catholic and Pentecostal contexts. The spiritual healing procedure implies a transit between spirituality and materiality, unlike the transcendental manifestation of the sacred that characterizes the miracle. This article aims, therefore, to provide an ethnographic contribution to the debates about the interface between health and spirituality through a focus on the ways in which this universe of meanings and practices is materialized in the experience of the attendants of a spiritist center.

Keywords: health; mediumship; miracle; spiritism; spiritual healing.

RECEBIDO: $18 / 02 / 2019$

APROVADO: $30 / 06 / 2019$ 